(2) Open Access Full Text Article

\title{
Illicit methylphenidate use among Iranian medical students: prevalence and knowledge
}

This article was published in the following Dove Press journal:

Drug Design, Development and Therapy

2 February 20II

Number of times this article has been viewed

\author{
Afshin Habibzadeh' \\ Mahasti Alizadeh² \\ Ayoub Malek ${ }^{3}$ \\ Leili Maghbooli' \\ Mohammadali M Shoja ${ }^{4}$ \\ Kamyar Ghabili ${ }^{4}$ \\ 'Students' Research Committee, \\ 2Department of Community \\ Medicine, ${ }^{3}$ Department of Psychiatry, \\ ${ }^{4}$ Tuberculosis and Lung Disease \\ Research Center, Tabriz University \\ of Medical Sciences, Tabriz, Iran
}

Background: Methylphenidate, a medication prescribed for individuals suffering from attentiondeficit/hyperactivity disorder, is increasingly being misused by students.

Objective: The aims of this study were to evaluate the frequency of methylphenidate use among a group of Iranian medical students and to assess their knowledge of methylphenidate.

Methods: Anonymous, self-administered questionnaires were completed by all medical students entering the university between 2000 and 2007.

Results: Methylphenidate users' mean knowledge score was higher than that of nonusers $(15.83 \pm 3.14$ vs $13.66 \pm 3.10, P=0.008)$. Age, gender, and school year were positively correlated with knowledge score $(P<0.05)$. Data analysis demonstrated that 27 participants $(8.7 \%)$ had taken methylphenidate at least once in their lifetime. The respondents believed that the most common motive for methylphenidate use among youths was that it aided concentration and therefore ability to study.

Conclusion: This study indicates a relatively low level of knowledge about methylphenidate among Iranian medical students. More educational programs regarding the use of methylphenidate are required and should be focused on the student suppliers, clinicians, pharmacists, and medical students.

Keywords: methylphenidate, medical student, prevalence, Iran

\section{Introduction}

According to the Diagnostic and Statistical Manual of Mental Disorders, 4th Edition, Text Revision (DSM-IV-TR), substance abuse is a mental disorder in which the use of a substance reaches a point th at induces significant dysfunction in the life of the abuser. ${ }^{1}$ Among such substances, prescription stimulants are assumed to be harmless ways of increasing levels of energy and concentration, enhancing school performance, or using for recreation, while lessening the desire for sleep. ${ }^{2}$ Youths show a high predilection for the use of prescription stimulants. ${ }^{3}$

Methylphenidate (Ritalin) is a medication prescribed for individuals, in particular children, who have attention-deficit/hyperactivity disorder (ADHD). ${ }^{4}$ The attentionimproving characteristic of methylphenidate has been attributed to the amplification of dopamine release in the central nervous system. ${ }^{5,6}$ There is an increasing trend toward the misuse of methylphenidate by youths. However, some research has concluded that methylphenidate use is exclusive to college students, because less use was found in a nonstudent population of the same age range. ${ }^{3}$ Methylphenidate is known for its high abuse potential; it has the same effects as cocaine or amphetamines ${ }^{5}$ and is the most widely researched of the prescription stimulant drugs. ${ }^{7,8}$ Cases of oral, intranasal,
Correspondence: Kamyar Ghabili Tuberculosis and Lung Disease Research Center, Tabriz University of Medical Sciences, Tabriz, Iran

Tel +989144106136

Fax +984113363846

Email kghabili@gmail.com 
and intravenous abuse of the drug are well documented..$^{9,10}$ The latter, a less common route of administration, can be precarious because fillers in the pills could block small blood vessels, causing injury to lungs and eyes. ${ }^{11}$ However, when methylphenidate is administered at high doses intranasally or orally, the risk of addiction increases and the physical side effects are augmented. ${ }^{5,9}$ No well-controlled studies have hitherto investigated methylphenidate tolerance, but clinicians and patients have reported situations where decreased efficacy and psychological dependence appear to occur. ${ }^{12}$

In recent years, researchers have investigated the illicit use of stimulants prescribed for the treatment of ADHD among American college students. ${ }^{13}$ Teter et al indicated that $3 \%$ of students surveyed at a large public university used methylphenidate for nonmedical purposes. ${ }^{14}$ Furthermore, Dupont et al reported that more than $5 \%$ of approximately 2000 college students used methylphenidate nonmedically at least once. ${ }^{15}$ Interestingly, Low and Gendaszek reported a prevalence of $35 \%$ among undergraduates in a psychology class for the misuse of methylphenidate or amphetamine. ${ }^{16}$ Prescription stimulant misuse ranges from $5 \%$ to $35 \%$ in college-aged individuals (for a review, see Wilens et $\mathrm{al}^{17}$ ). Demanding times throughout the academic year, including final examinations, can lead to an increased demand for prescription stimulants such as methylphenidate..$^{9,17}$ Appetite suppression, wakefulness, increased attentiveness, and euphoria are known to be stimulant effects of methylphenidate. $^{5}$

These data provide some understanding of the prevalence of methylphenidate abuse, particularly in the US and Canada. No corresponding data are available from other countries, and an in-depth description of the users' conceptions and choices is lacking. A few recent studies have focused on various health topics among Iranian medical students, ${ }^{18-20}$ but there has been no research examining the prevalence and correlation of nonmedical use of methylphenidate among such students. Therefore, this study was carried out to determine the frequency of methylphenidate use among a group of Iranian medical students and to assess their knowledge of methylphenidate.

\section{Methods}

The study population comprised all medical students entering the Faculty of Medicine, Tabriz University of Medical Sciences, Tabriz, Iran, between 2000 and 2007. A selfadministered, anonymous questionnaire based on information obtained from a review of the literature on methylphenidate was utilized. The questionnaires were distributed among all the medical students from the first (2007 entrance) to seventh (2000 entrance) school year who were present at daily classes and/or hospital wards between January and March 2007. The reliability and validity of the questionnaire were qualified and examined by a pilot study and the supervision of expert professors. The questionnaire comprised four sections: 1) demographic information including age, gender, marital status, living place, and average grade of participants (five items); 2) methylphenidate-related questions covering general information, clinical symptoms, and legal aspects (11 items); 3) questions to determine the frequency of methylphenidate use (two items); and 4) a multiple-choice question regarding the respondents' perceptions of the reasons for the increasing tendency toward methylphenidate use (one item).

Concerning knowledge about methylphenidate, the section began with a question on whether individuals had heard of methylphenidate. This was followed by a question about the source of the respondents' information (mass media, medical books, scientific journals, Internet, friends, or a physician's prescription). In addition, there were 11 statements concerning students' knowledge of methylphenidate, and possible responses for this section included "true", "false", and "I don't know". The knowledge score was calculated by allocating +2 for a correct answer, 0 for an incorrect answer, and +1 for "I don't know" responses. A total of 22 points could be achieved if all questions were answered correctly. Higher scores were indicative of a greater level of knowledge.

In order to determine the frequency of methylphenidate use among the students, they were asked whether they had used methylphenidate, excluding those who had been prescribed the medication. If respondents replied in the affirmative to this question they answered a follow-up question relating to how often they used methylphenidate. Possible responses for this question included "used before last year", "used in the past 12 months", "used in the past 6 months", and "used in the past 30 days". In addition, a question relating to the preferred route of administration was included in the questionnaire.

Additional questions concerning the reasons for taking prescription stimulant medications were posed to all respondents. Students were given the option to choose any of the response categories including increasing wakefulness, peer pressure, curiosity, increasing self-confidence, weight loss, increasing concentration, and euphoric effects.

Data were presented as the mean \pm standard deviation, or percentage when appropriate. All statistical analyses 
were performed with SPSS (SPSS Inc, Chicago, IL, USA) for Windows, Version 16.0, using a Chi-square test, Fisher's exact test, and independent samples $t$-test. Spearman's correlation coefficient was calculated to determine the correlation between quantitative variables (demographic items and total knowledge score). A $P$ value $<0.05$ was considered statistically significant.

\section{Results}

Of 500 medical students, 310 completed the questionnaire, representing a response rate of $62 \%$. The mean age of the respondents was $21.4 \pm 2.07$ years (range 18-28 years). Fortythree percent $(n=134)$ of the students were male and $56.7 \%$ $(\mathrm{n}=176)$ were female. The students' mean grade average was $15.4 \pm 1.3$ out of 20 (range 12.4-18.8). A list of the knowledge questions with the percentage of each response is provided in Table 1. Methylphenidate users' mean knowledge score (total of correct and incorrect responses) was higher than that of nonusers ( $15.83 \pm 3.14$ vs $13.66 \pm 3.10$, Table $2, P=0.008)$. Among the demographic items, age $(r=0.29 ; P=0.001)$, gender $(r=0.22 ; P=0.015)$, and school year $(r=0.28$; $P=0.001)$ were positively correlated with the knowledge score. There was no significant correlation between other demographic items (grade average, marital status, and place of residence) and knowledge score $(P>0.05)$.

Data analysis demonstrated that 27 participants $(8.7 \%)$ had taken methylphenidate at least once in their lifetime; two students were excluded from the study because they misused methylphenidate while under a physician's order. Of these 27 individuals, 20 (74\%) declared that they had taken methylphenidate within the last year and three (11\%) within the last month. Ninety-seven participants (31.2\%) knew someone among their classmates and friends who had misused methylphenidate. The frequency of methylphenidate use was significantly higher among men than among women $(92 \%$ vs $8 \%$, Table $2, P<0.001)$. Furthermore, methylphenidate use was significantly higher among respondents with a grade average of 15 or less $(74 \%)$ than among students with higher grade averages (Chi-square test, $P<0.001)$. Methylphenidate had previously been prescribed by physicians for three of the users $(11 \%)$, and six students $(22.2 \%)$ indicated that they were encouraged by their peers to take methylphenidate for its positive effects. The preferred route of administration was oral $(88.8 \%)$, followed by nasal (3.7\%) and injection (3.7\%). Many of the respondents $(21 \%)$ indicated that friends were the major source of information concerning methylphenidate, followed by scientific books and journals (17.6\%), mass media (radio, television, and newspapers) $(4.2 \%)$, and the Internet $(3.4 \%)$. The data from respondents and methylphenidate users are provided in Table 2.

Respondents believed that the most common motive for methylphenidate use was to increase concentration (41.7\%). Furthermore, students declared that increasing wakefulness $(17.3 \%)$, curiosity $(16.7 \%)$, increasing energy levels $(8.8 \%)$, increasing self-confidence $(6.1 \%)$, peer pressure (5\%), and weight loss $(4.4 \%)$ were also common reasons for methylphenidate misuse.

\section{Discussion}

In the present study, the prevalence of methylphenidate misuse among a group of Iranian medical students was assessed along with their knowledge of methylphenidate. Data analysis demonstrated that less than $9 \%$ of medical students had used methylphenidate at least once in their lifetime. Of those who admitted to using the drug, approximately $75 \%$ had taken methylphenidate in the past year and $10 \%$ in the last 30 days. A wide range of

Table I The respondents' knowledge of methylphenidate $(n=310)$

\begin{tabular}{|c|c|c|c|}
\hline Statement & True (\%) & False (\%) & I do not know (\%) \\
\hline I. Methylphenidate is an illicit prescription drug. & 44.9 & 40.8 & 14.2 \\
\hline 2. Methylphenidate carriers are criminal. & 32.9 & 10.7 & 56.2 \\
\hline 3. Increased concentration is one of its positive effects. & 50 & 3.2 & 45.7 \\
\hline $\begin{array}{l}\text { 4. A person who uses methylphenidate can have high mental activity } \\
\text { for hours without needing to relax. }\end{array}$ & 40.4 & 5.9 & 53.5 \\
\hline 5. Methylphenidate is advised for weight loss. & 13.2 & 10.8 & 75.9 \\
\hline 6. Positive effects of methylphenidate last only several hours. & 39 & 6 & 54.8 \\
\hline 7. Methylphenidate has no medical use. & 45.7 & $\mathrm{II} .4$ & 43.3 \\
\hline 8. Methylphenidate can cause increased hunger. & 19.2 & 7.8 & 72.8 \\
\hline 9. Methylphenidate decreases learning. & 31.3 & 7.8 & 60.8 \\
\hline 10. Methylphenidate causes low heart rate. & 29.1 & 8.6 & 62.1 \\
\hline $\begin{array}{l}\text { II. Methylphenidate has no characteristics of addictive drugs and users } \\
\text { do not become dependent. }\end{array}$ & 37.3 & 8.4 & 54.2 \\
\hline
\end{tabular}


Table 2 Students' and illicit methylphenidate users' demographic characteristics

\begin{tabular}{|c|c|c|c|}
\hline Student characteristics & $\begin{array}{l}\text { All the respondents } \\
(n=3 \mid 0)\end{array}$ & $\begin{array}{l}\text { Methylphenidate users } \\
(\mathrm{n}=27)\end{array}$ & $P$ value \\
\hline Age (years) & $21.41 \pm 2.07$ & $21.94 \pm 2.12$ & $0.33^{b}$ \\
\hline Grade average (out of total 20 ) & $15.48 \pm 1.30$ & $14.31 \pm 1.50$ & $<\left.0.00\right|^{\mathrm{a}, \mathrm{b}}$ \\
\hline Knowledge score & $13.87 \pm 3.17$ & $15.83 \pm 3.14$ & $0.008^{\mathrm{a}, \mathrm{b}}$ \\
\hline \multicolumn{4}{|l|}{ Gender, n (\%) } \\
\hline Male & $134(43.3)$ & $25(92.5)$ & $<\left.0.00\right|^{a, c}$ \\
\hline Female & $176(56.7)$ & $2(7.5)$ & \\
\hline \multicolumn{4}{|l|}{ Marital status, n (\%) } \\
\hline Married & $17(5.5)$ & $0(0)$ & $0.29^{c}$ \\
\hline Single & $293(94.5)$ & $27(100)$ & \\
\hline \multicolumn{4}{|l|}{ Place of residence, $n(\%)$} \\
\hline With family & $129(4 \mid .7)$ & $7(26)$ & $0.59^{d}$ \\
\hline Dormitory & $144(46.4)$ & $18(66.6)$ & \\
\hline Rented house & $37(11.9)$ & $2(7.4)$ & \\
\hline \multicolumn{4}{|l|}{ School year, n (\%) } \\
\hline Ist year & $56(18.1)$ & $2(7.4)$ & $0.17^{\mathrm{d}}$ \\
\hline 2nd year & $21(6.8)$ & $4(14.8)$ & \\
\hline 3 rd year & $69(22.1)$ & $6(22.2)$ & \\
\hline 4th year & $56(18.1)$ & $7(26)$ & \\
\hline 5 th year & $56(18.1)$ & $4(14.8)$ & \\
\hline 6th year & $31(10)$ & $0(0)$ & \\
\hline 7th year & $21(6.8)$ & $4(14.8)$ & \\
\hline
\end{tabular}

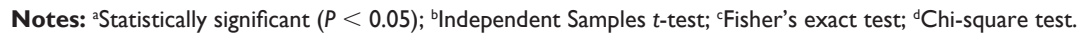

methylphenidate use has been reported in the literature. ${ }^{13,17}$ Teter et al surveyed a large sample of public university students among whom 3\% indicated nonmedical use of methylphenidate within the previous year. ${ }^{14}$ According to the Monitoring the Future (MTF) study, annual use of methylphenidate among college students was $4.2 \%$ and $3.9 \%$ in 2005 and 2006, respectively. ${ }^{3}$ In another study by Teter et al, approximately $25 \%$ of illicit users of prescription stimulants used methylphenidate. ${ }^{21}$ In contrast, Low and Gendaszek indicated that $35 \%$ of 150 undergraduates in a psychology class had used either methylphenidate or amphetamine at least once. ${ }^{16}$ In the present study, approximately $30 \%$ of respondents knew someone among their classmates and friends who had misused methylphenidate. The difference between the two calculated prevalences of methylphenidate use among the surveyed group of medical students $(8.8 \% \mathrm{vs}$ $31.2 \%$ ) might suggest that students felt more comfortable about reporting methylphenidate use by their peers than by themselves, despite the anonymity of the questionnaires. However, this difference could also be due to overlap between the reports, ie, one particular methylphenidate user could be reported by himself/herself and his/her friends simultaneously. To the best of our knowledge, the present study is the first survey to determine the frequency of methylphenidate misuse among a group of medical students and to assess their knowledge of methylphenidate.
The overall findings from this study indicate a relatively low level of knowledge concerning methylphenidate, its physiological and psychological side effects, or legal consequences of illicit use among the medical students surveyed. However, the students' knowledge score increased the longer they had been studying at the university. Assessing the knowledge of the university students with regard to methylphenidate has been neglected in most previous research, though DeSantis et al indicated that most users among undergraduates at a southeastern research university in the US possessed limited knowledge of prescription stimulants, including methylphenidate. ${ }^{13}$

In accordance with the MTF study, men reported higher past-year rates of methylphenidate misuse than women did. $^{3}$ Hall et $\mathrm{al}^{22}$ and Simoni-Wastila ${ }^{23}$ found a comparable gender difference in the misuse of methylphenidate. This study presented a comparable finding, but the frequency of methylphenidate misuse among men was much higher than among women $(92 \%$ vs $8 \%)$. In contrast, Teter et al reported that undergraduate men and women used illicit methylphenidate equally. ${ }^{14}$ In the present study, medical students with lower grade point averages were more likely to use methylphenidate illicitly. This finding is similar to those of the surveys carried out by McCabe et al. ${ }^{24,25}$ Furthermore, in the present study, methylphenidate use was reported most frequently among single medical students who resided on campus, but this was not statistically significant. 
Individuals misuse methylphenidate and other stimulants to keep alert and improve concentration as they prepare for tests or complete term papers. ${ }^{26}$ Teter et al reported that the majority of methylphenidate users among surveyed students used methylphenidate to enhance their academic performance by increasing concentration and alertness. ${ }^{27}$ Two recent surveys of Iranian pharmacists and general practitioners demonstrated that the majority of the respondents believed that Ritalin was used to increase attention and concentration. ${ }^{28,29}$ Likewise, in this study, the majority of the respondents, including the methylphenidate users, highlighted that increased concentration was the most common motive for the use of methylphenidate. However, Barrett et al stated that $70 \%$ of methylphenidate users administered it for recreational reasons. ${ }^{10}$

In the present study, the most common routes of methylphenidate administration were oral (89\%), intranasal $(3.7 \%)$, and injection (3.7\%). The predominantly oral methylphenidate misuse in this study is consistent with previous reports. ${ }^{10,15,21,30}$ Interestingly, Teter et al reported smoking as another route of methylphenidate administration, but this was not evident in the present research. ${ }^{21}$ In the present study, friends were the main source of information. This finding is in contrast to our previous reports concerning medical and female high school students' knowledge of bird flu $^{18}$ and HIV/AIDS ${ }^{31}$ in the same city, which revealed that the mass media were the main source of information..$^{18,31}$ In previous reports, Iranian pharmacists and general practitioners stated that they obtained information on methylphenidate from the mass media and medical journals. ${ }^{28,29}$

This study has certain limitations. First, the validity of self-reported methylphenidate use among respondents depends on their willingness to reply truthfully on the questionnaire. Second, the sample in the present study was from a single university, thereby necessitating similar studies be conducted in other medical schools for comparison. Third, the present study did not explicitly address duration or frequency of methylphenidate use. Therefore, it is unknown whether nonprescription users took methylphenidate regularly or only occasionally. Fourth, the response rate in the present study was relatively low $(62 \%)$. It is possible that the prevalence of methylphenidate misuse was underestimated if those who misused the drug chose not to complete the survey (eg, for fear of lack of anonymity). However, it should be highlighted that this study is the first to estimate the prevalence of methylphenidate use among medical students.

As methylphenidate is legally available to a small group of students (student suppliers) as ADHD medication, the authors believe that focusing on the small group of student suppliers may be an effective intervention approach to addressing the current problem of methylphenidate misuse among university students. Hence, the medical community, including clinicians and pharmacists, may consider reducing the monthly allocation of pills. In addition, clinicians should counsel students regarding the probable serious adverse effects to health if methylphenidate is misused, as well as the potential legal consequences of misuse. Furthermore, training health care professionals and medical students is of great importance in controlling the current trend. The findings of this study should be considered seriously by local health centers. Being aware of the scope and context of the problem could aid the development of prevention and monitoring programs for prescription drug misuse and diversion. The relatively low level of knowledge concerning methylphenidate among medical students in this study is primarily a reflection of insufficient academic courses in the medical school curriculum. It is recommended that knowledge of medical students about this topic be improved through access to textbooks, articles, seminars, and specific courses. Moreover, the addition of the topic of stimulant drugs, including methylphenidate, to pharmacology, toxicology, and psychiatry courses during medical education is advised.

\section{Acknowledgments}

This research was financially supported by the Vice Chancellor for Research, Tabriz University of Medical Sciences, Tabriz, Iran. The authors are indebted to the Students' Research Committee (SRC), Tabriz University of Medical Sciences, Iran, for its support. The authors are grateful to Dr Paul S Agutter for his critical review of this manuscript.

\section{Disclosure}

No conflicts of interest were declared in relation to this paper.

\section{References}

1. American Psychiatric Association. Diagnostic and Statistical Manual of Mental Disorders, 4th Edition, Text Revision. Washington, DC: American Psychiatric Publishing; 2000.

2. Kadison R. Getting an edge-use of stimulants and antidepressants in college. N Engl J Med. 2005;353:1089-1091.

3. Johnston LD, O'Malley PM, Bachman JG, Schulenberg JE. Monitoring the Future National Survey Results on Drug use, 1975-2006: Volume II, College Students and Adults Ages 19-45. NIH Publication No. 07-6206. Bethesda, MD: National Institute on Drug Abuse; 2007.

4. Greenhill LL, Pliszka S, Dulcan MK, et al. Practice parameter for the use of stimulant medications in the treatment of children, adolescents, and adults. J Am Acad Child Adolesc Psychiatry. 2002;41(2 Suppl) 26S-49S. 
5. National Institute on Drug Abuse. Bethesda, MD: NIDA InfoFacts: stimulant ADHD medications - methylphenidate and amphetamines. Available from: http://www.drugabuse.gov/Infofacts/ADHD.html. Accessed Dec 172010.

6. Volkow ND, Fowler JS, Wang G, Ding Y, Gatley SJ. Mechanism of action of methylphenidate: insights from PET imaging studies. J Atten Disord. 2002;6(Suppl 1):S31-S43.

7. The Higher Education Center for Alcohol and Other Drug Prevention. Newton, Massachusetts: recreational use of Ritalin on college campuses. Available from: http://www.higheredcenter.org/files/product/ritalin.pdf. Accessed 2010 Dec 17.

8. Klein-Schwartz W. Abuse and toxicity of methylphenidate. Curr Opin Pediatr. 2002;14:219-223.

9. Kollins SH, MacDonald EK, Rush CR. Assessing the abuse potential of methylphenidate in nonhuman and human subjects: a review. Pharmacol Biochem Behav. 2001;68:611-627.

10. Barrett SP, Darredeau C, Bordy LE, Pihl RO. Characteristics of methylphenidate misuse in a university student sample. Can J Psychiatry. 2005;50:457-461.

11. Parran TV Jr, Jasinski DR. Intravenous methylphenidate abuse. Prototype for prescription drug abuse. Arch Intern Med. 1991;151:781-783.

12. Sallee FR, Gill HS. Neuropsychopharmacology III: psychostimulants. In: Coffey CE, Brumback RA, editors. Textbook of Pediatric Neuropsychiatry. Washington, DC: American Psychiatric Press; 1998: 1351-1372.

13. DeSantis AD, Webb EM, Noar SM. Illicit use of prescription ADHD medications on a college campus: a multimethodological approach. J Am Coll Health. 2008;57:315-324.

14. Teter CJ, McCabe SE, Boyd CJ, Guthrie SK. Illicit methylphenidate use in an undergraduate student sample: prevalence and risk factors. Pharmacotherapy. 2003;23:609-617.

15. Dupont RL, Coleman JJ, Bucher RH, Wilford BB. Characteristics and motives of college students who engage in nonmedical use of methylphenidate. Am J Addict. 2008;17:167-171.

16. Low KG, Gendaszek AE. Illicit use of psychostimulants among college students: a preliminary study. Psychol Health Med. 2002;7:283-287.

17. Wilens TE, Adler LA, Adams J, et al. Misuse and diversion of stimulants prescribed for ADHD: a systematic review of the literature. J Am Acad Child Adolesc Psychiatry. 2008;47:21-31.
18. Ghabili K, Shoja MM, Kamran P. Avian influenza knowledge among medical students, Iran. Emerg Infect Dis. 2008;14:672-673.

19. Ghabili K, Alizadeh M. Computer and Internet use among Iranian medical students. Med Educ. 2008;42:114.

20. Alizadeh M, Ghabili K. Health related life style among the Iranian medical students. Res J Biol Sci. 2008;3:4-9.

21. Teter CJ, McCabe SE, LaGrange K, Cranford JA, Boyd CJ. Illicit use of specific prescription stimulants among college students: prevalence, motives, and routes of administration. Pharmacotherapy. 2006;26: 1501-1510.

22. Hall KM, Irwin MM, Bowman KA, Frakenberger W, Jewett DC. Illicit use of prescribed stimulant medication among college students. J Am Coll Health. 2005;53:167-174.

23. Simoni-Wastila L. The use of abusable prescription drugs: the role of gender. J Womens Health Gend Based Med. 2000;9:289-297.

24. McCabe SE, Teter CJ, Boyd CJ, Guthrie SK. Prevalence and correlates of illicit methylphenidate use among 8th, 10th, and 12th grade students in the United States, 2001. J Adolescent Health. 2004;35:501-504.

25. McCabe SE, Knight JR, Teter CJ, Wechsler H. Non-medical use of prescription stimulants among US college students: prevalence and correlates from a national survey. Addiction. 2005;100:96-106.

26. Safer DJ. Are stimulants overprescribed for youths with ADHD? Ann Clin Psychiatry. 2000;12:55-62.

27. Teter CJ, McCabe SE, Cranford JA, Boyd CJ, Guthrie SK. Prevalence and motives for illicit use of prescription stimulants in an undergraduate student sample. J Am Coll Health. 2005;53:253-262.

28. Ghanizadeh A. Knowledge of pharmacists regarding ritalin and ADHD and their attitude towards the use of ritalin to treat ADHD. Int $J$ Clin Pharmacol Ther. 2008;46:84-88.

29. Ghanizadeh A, Zarei N. Are GPs adequately equipped with the knowledge for educating and counseling of families with ADHD children? BMC Fam Pract. 2010;11:5.

30. White BP, Becker-Blease KA, Grace-Bishop K. Stimulant medication use, misuse, and abuse in an undergraduate and graduate student sample. J Am Coll Health. 2006;54:261-268.

31. Ghabili K, Shoja MM, Kamran P. The Iranian female high school students' attitude towards people with HIV/AIDS: a cross-sectional study. AIDS Res Ther. 2008;5:15.
Drug Design, Development and Therapy

\section{Publish your work in this journal}

Drug Design, Development and Therapy is an international, peerreviewed open-access journal that spans the spectrum of drug design and development through to clinical applications. Clinical outcomes, patient safety, and programs for the development and effective, safe, and sustained use of medicines are a feature of the journal, which

\section{Dovepress}

has also been accepted for indexing on PubMed Central. The manuscript management system is completely online and includes a very quick and fair peer-review system, which is all easy to use. Visit http://www.dovepress.com/testimonials.php to read real quotes from published authors. 